\title{
Measurement properties of translated versions of neck-specific questionnaires: a systematic review
}

Jasper M Schellingerhout ${ }^{1 *}$, Martijn W Heymans ${ }^{2,3+}$, Arianne P Verhagen ${ }^{1 \dagger}$, Henrica C de Vet ${ }^{2+}$, Bart W Koes ${ }^{1 \dagger}$ and Caroline B Terwee ${ }^{2 \dagger}$

\begin{abstract}
Background: Several disease-specific questionnaires to measure pain and disability in patients with neck pain have been translated. However, a simple translation of the original version doesn't guarantee similar measurement properties. The objective of this study is to critically appraise the quality of the translation process, cross-cultural validation and the measurement properties of translated versions of neck-specific questionnaires.

Methods: Bibliographic databases were searched for articles concerning the translation or evaluation of the measurement properties of a translated version of a neck-specific questionnaire. The methodological quality of the selected studies and the results of the measurement properties were critically appraised and rated using the COSMIN checklist and criteria for measurement properties.

Results: The search strategy resulted in a total of 3641 unique hits, of which 27 articles, evaluating 6 different questionnaires in 15 different languages, were included in this study. Generally the methodological quality of the translation process is poor and none of the included studies performed a cross-cultural adaptation. A substantial amount of information regarding the measurement properties of translated versions of the different neck-specific questionnaires is lacking. Moreover, the evidence for the quality of measurement properties of the translated versions is mostly limited or assessed in studies of poor methodological quality.

Conclusions: Until results from high quality studies are available, we advise to use the Catalan, Dutch, English, Iranian, Korean, Spanish and Turkish version of the NDI, the Chinese version of the NPQ, and the Finnish, German and Italian version of the NPDS. The Greek NDI needs cross-cultural validation and there is no methodologically sound information for the Swedish NDI. For all other languages we advise to translate the original version of the $\mathrm{NDI}$.
\end{abstract}

\section{Background}

Several disease-specific questionnaires have been developed to measure pain and disability in patients with neck pain (e.g. Neck Disability Index (NDI), Neck Pain and Disability Scale (NPDS)) [1,2]. To make them suitable for use in other languages, several of these neck-specific questionnaires have been translated. However, a simple translation of the original version doesn't guarantee similar measurement properties, because differences in cultural context have to be taken into account as well $[3,4]$.

\footnotetext{
* Correspondence: j.schellingerhout@erasmusmc.nl

+ Contributed equally

'Department of General Practice, Erasmus Medical Centre, Rotterdam,

The Netherlands

Full list of author information is available at the end of the article
}

Previous reviews of neck-specific questionnaires have not paid sufficient attention to possible differences in performance, caused by differences in cultural context, and combine the results of studies that evaluate measurement properties of different language versions of the same questionnaire [5,6]. This may lead to inconsistent results for measurement properties, as was demonstrated in a recent review of the cross-cultural adaptations of the McGill Pain Questionnaire [7].

Since it is possible that the measurement properties of neck-specific questionnaires vary between different nationalities, we decided to evaluate them per language. This reduces inconsistency in results due to cultural differences and also facilitates a choice for the best questionnaire per language. The measurement properties of original versions of the different neck-specific
C Biomed Central

() 2011 Schellingerhout et al; licensee BioMed Central Ltd. This is an Open Access article distributed under the terms of the Creative Commons Attribution License (http://creativecommons.org/licenses/by/2.0), which permits unrestricted use, distribution, and reproduction in any medium, provided the original work is properly cited. 
questionnaires were evaluated in a separate systematic review. (Schellingerhout JM, Heymans MW, Verhagen AP, De Vet HC, Koes BW, Terwee CB: Measurement properties of disease-specific questionnaires in patients with neck pain: a systematic review, submitted)

The purpose of this study is to critically appraise the quality of the translation process, cross-cultural validation and the measurement properties of translated versions of neck-specific questionnaires.

\section{Methods}

\section{Search strategy}

We searched the following computerised bibliographic databases: Medline (1966 to July 2010), EMbase (1974 to July 2010), CINAHL (1981 to July 2010), and PsycINFO (1806 to July 2010). We used the index terms "neck", "neck pain", and "neck injuries/injury" in combination with "research measurement", "questionnaire", "outcome assessment", "psychometry", "reliability", "validity", and derivatives of these terms. The full search strategy used in each database is available upon request from the corresponding author. Reference lists were screened to identify additional relevant studies.

\section{Selection criteria}

A study was included if it was a full text original article (e.g. not an abstract, review or editorial), published in English, concerning the translation or evaluation of the measurement properties of a translated version of a neck-specific questionnaire. The questionnaire had to be self-reported, evaluating pain and/or disability, and specifically developed or adapted for patients with neck pain.

For inclusion, neck pain had to be the main complaint of the study population. Accompanying complaints (e.g. low back pain or shoulder pain) were no reason for exclusion, as long as the main focus was neck pain. Studies considering study populations with a specific neck disorder (e.g. neurological disorder, rheumatological disorder, malignancy, infection, or fracture) were excluded, except for patients with cervical radiculopathy or whiplash associated disorder (WAD).

Two reviewers (JMS, APV) independently assessed the titles, abstracts, and reference lists of studies retrieved by the literature search. In case of disagreement between the two reviewers, there was discussion to reach consensus. If necessary, a third reviewer (HCV) made the decision regarding inclusion of the article.

\section{Measurement properties}

The measurement properties are divided over three domains: reliability, validity, and responsiveness [8]. In addition, the interpretability is described.

\section{Reliability}

Reliability is defined as the extent to which scores for patients who have not changed are the same for repeated measurement under several conditions: e.g. using different sets of items from the same questionnaire (internal consistency); over time (test-retest); by different persons on the same occasion (inter-rater); or by the same persons on different occasions (intra-rater) [8].

Reliability contains the following measurement properties:

- Internal consistency: The interrelatedness among the items in a questionnaire, expressed by Cronbach's $\alpha$ or Kuder-Richardson Formula 20 (KR-20) $[8,9]$.

- Measurement error: The systematic and random error of a patient's score that is not attributed to true changes in the construct to be measured, expressed by the standard error of measurement (SEM) $[8,10]$. The SEM can be converted into the smallest detectable change (SDC) [10]. Changes exceeding the SDC can be labeled as change beyond measurement error [10]. Another approach is to calculate the limits of agreement (LoA) [11]. For determining the adequacy of measurement error the SDC and/or LoA is related to the minimal important change (MIC) [12].

- Reliability: The proportion of the total variance in the measurements which is due to 'true' differences between patients [8]. This aspect is reflected by the Intraclass Correlation Coefficient (ICC) or Cohen's Kappa $[8,13]$.

\section{Validity}

Validity is the extent to which a questionnaire measures the construct it is supposed to measure and contains the following measurement properties [8]:

- Content validity: The degree to which the content of a questionnaire is an adequate reflection of the construct to be measured [8]. Important aspects are whether all items are relevant for the construct, aim, and target population and if no important items are missing (comprehensiveness) [14].

- Criterion validity: The extent to which scores on an instrument are an adequate reflection of a gold standard [8]. Since a real gold standard for health status questionnaires is not available, [14] we will not evaluate criterion validity.

- Construct validity is divided into three aspects:

- Cross-cultural validity: The degree to which the performance of the items on a translated or culturally adapted instrument are an adequate reflection of the performance of the items of the 
original version of the instrument [8]. This is assessed by means of multi-group factor analysis or differential item functioning using data from a population that completed the questionnaire in the original language, as well as data from a population that completed the questionnaire in the new language.

- Structural validity: The degree to which the scores of an instrument are an adequate reflection of the dimensionality of the construct to be measured [8]. Factor analysis should be performed to confirm the number of subscales present in a questionnaire [14].

- Hypothesis testing: The degree to which a particular measure relates to other measures in a way one would expect if it is validly measuring the supposed construct, i.e. in accordance with predefined hypotheses about the correlation or differences between the measures [8].

\section{Responsiveness}

Responsiveness is the ability of an instrument to detect change over time in the construct to be measured [8]. Responsiveness is considered an aspect of validity, in a longitudinal context [14]. Therefore, the same standards apply as for validity: the correlation between change scores of two measures should be in accordance with predefined hypotheses [14]. Another approach is to consider the measurement instrument as a diagnostic test to distinguish improved and non-improved patients. The responsiveness of the instrument is then expressed as the area under the receiver operator characteristic curve (AUC) [14].

\section{Interpretability}

Interpretability is the degree to which one can assign qualitative meaning to quantitative scores [8]. This means that investigators should provide information about clinically meaningful differences in scores between subgroups, floor and ceiling effects, and the MIC [14]. Interpretability is not a measurement property, but an important characteristic of a measurement instrument [8].

\section{Quality assessment}

Assessment of the methodological quality of the selected studies was carried out using the COSMIN checklist [9]. The COSMIN checklist consists of nine boxes with methodological standards for how each measurement property should be assessed. Each item was scored on a 4-point rating scale (i.e. "poor", "fair", "good", or "excellent", see http://www.cosmin.nl). An overall score for the methodological quality of a study was determined by taking the lowest rating of any of the items in a box. The methodological quality of a study was evaluated per measurement property. Special attention was paid to the methodological quality of the translation process and cross-cultural validation. The COSMIN box concerning this measurement property is presented in Table 1.

Data extraction and assessment of (methodological) quality were performed by two reviewers (JMS, CBT) independently. In case of disagreement between the two reviewers, there was discussion in order to reach consensus. If necessary, a third reviewer (HCV) made the decision.

\section{Best evidence synthesis - levels of evidence}

To determine the overall quality of the measurement properties of the different questionnaires we synthesized the different studies per language by combining their results, adjusted for methodological quality of the studies and the consistency of their results. The possible overall rating for a measurement property is "positive", "indeterminate", or "negative", accompanied by levels of evidence, similarly as was proposed by the Cochrane Back Review Group (see Table 2) $[15,16]$.

To assess whether the results of the measurement properties were positive, negative, or indeterminate, we used criteria based on Terwee et al. (see Table 3) [17].

\section{Results}

The search strategy resulted in a total of 3641 unique hits, of which 119 articles were selected based on their title and abstract. The full text assessment resulted in exclusion of another 68 articles. Reference checking did not result in additional articles. Twenty-four articles concerned original versions of neck-specific questionnaires, which were evaluated in a separate systematic review. (Schellingerhout JM, Heymans MW, Verhagen AP, De Vet HC, Koes BW, Terwee CB: Measurement properties of disease-specific questionnaires in patients with neck pain: a systematic review, submitted) Finally, 27 articles on translated questionnaires, evaluating 6 different questionnaires in 15 different languages, were included in this study (see Figure 1).

The general characteristics of these studies are presented in Table 4. None of the included studies performed a cross-cultural validation (Table 1, items 14 and 15), i.e. no studies performed multi-group factor analysis or differential item functioning. Therefore, we were only able to rate the methodological quality of the translation process (Table 1, items 4-11). The methodological quality of the studies is presented in Table 5 for each measurement property, arranged per language. Generally the methodological quality of the studies was poor to fair. The synthesis of the results per questionnaire and their accompanying level of evidence is presented in Table 6 for each language. For each questionnaire, except for the Iranian NPDS and Spanish NDI, at least half of the information regarding 
Table 1 Methodological criteria for the translation process and cross-cultural validation [9]

\begin{tabular}{|c|c|}
\hline Item & Methodological Criteria \\
\hline 1 & Was the percentage of missing items given? \\
\hline 2 & Was there a description of how missing items were handled? \\
\hline 3 & Was the sample size included in the analysis adequate? \\
\hline 4 & $\begin{array}{l}\text { Were both the original language in which the HR-PRO instrument was developed, } \\
\text { and the language in which the HR-PRO instrument was translated described? }\end{array}$ \\
\hline 5 & Was the expertise of the people involved in the translation process adequately described? \\
\hline & e.g. expertise in the disease(s) involved, in the construct to be measured, or in both languages \\
\hline 6 & Did the translators work independently from each other? \\
\hline 7 & Were items translated forward and backward? \\
\hline 8 & $\begin{array}{l}\text { Was there an adequate description of how differences between the original and } \\
\text { translated versions were resolved? }\end{array}$ \\
\hline 9 & Was the translation reviewed by a committee (e.g. original developers)? \\
\hline 10 & $\begin{array}{l}\text { Was the HR-PRO instrument pre-tested (e.g. cognitive interviews) to check interpretation, } \\
\qquad \text { cultural relevance of the translation, and ease of comprehension? }\end{array}$ \\
\hline 11 & Was the sample used in the pre-test adequately described? \\
\hline 12 & Were the samples similar for all characteristics except language and/or cultural background? \\
\hline 13 & Were there any important flaws in the design or methods of the study? \\
\hline 14 & for CTT: Was confirmatory factor analysis performed? \\
\hline 15 & for IRT: Was differential item function (DIF) between language groups assessed? \\
\hline
\end{tabular}

$\mathrm{CTT}=$ Classical Test Theory, IRT = Item Response Theory

measurement properties is lacking. Moreover, the evidence for the quality of measurement properties is mostly limited, due to methodological shortcomings of the included studies.

Below we will discuss the results for the different questionnaires per language. The results regarding measurement properties from studies of poor methodological quality are not mentioned [18-24].

\section{Catalan}

The NDI is the only neck-specific questionnaire that has been translated in Catalan [25]. The NDI was originally designed to measure activities of daily living (ADL) in

Table 2 Levels of evidence for the overall quality of the measurement property [16]

\begin{tabular}{|c|c|c|}
\hline Level & Rating & Criteria \\
\hline \multirow[t]{3}{*}{ strong } & +++ or & Consistent findings in multiple studies of good \\
\hline & & $\begin{array}{c}\text { methodological quality OR in one study of } \\
\text { excellent }\end{array}$ \\
\hline & & methodological quality \\
\hline \multirow[t]{2}{*}{ moderate } & ++ or - & $\begin{array}{l}\text { Consistent findings in multiple studies of fair } \\
\text { methodological quality OR in one study of } \\
\text { good }\end{array}$ \\
\hline & & methodological quality \\
\hline limited & + or - & One study of fair methodological quality \\
\hline conflicting & $+/-$ & Conflicting findings \\
\hline unknown & $?$ & Only studies of poor methodological quality \\
\hline
\end{tabular}

[..] $=$ reference number

$+=$ positive result, $-=$ negative result patients with neck pain [1]. The methodological quality of the translation process is poor [25]. Confirmatory factor analysis showed that the NDI is not unidimensional and there is limited evidence that the NDI has a 2-factor structure [25]. Assuming a 2-factor structure, there is moderate positive evidence for internal consistency: Cronbach's $\alpha$ is 0.70 for "pain and interference with cognitive functioning" and 0.83 for "functional disability" [25]. There is a positive correlation $(\mathrm{r}=0.51)$ between the NDI and the Pain Intensity Index [25].

The available evidence on measurement properties of the Catalan NDI is positive, despite the poor methodological quality of the translation process.

\section{Chinese}

The Northwick Park Neck Pain Questionnaire (NPQ) is the only neck-specific questionnaire that has been translated in Chinese [26-28]. The NPQ was originally designed to measure the influence of non-specific neck pain on daily activities [29]. The methodological quality of the translation process is poor [26].

There is strong positive evidence for the reliability of the NPQ (ICC = 0.95) [26]. Hypothesis testing resulted in moderate positive evidence for correlation between the NPQ and instruments measuring pain and physical functioning $(r=0.59-0.75)$ [26,27]. Differences in score between subgroups have been reported (e.g. healthy persons vs. neck pain patients, and patients who sought medical consultation vs. those who did not) [26]. The average time needed to fill out the NPQ is 5.5 minutes [26]. 
Table 3 Quality criteria for measurement properties [Based on Terwee et al., [17]]

\begin{tabular}{|c|c|c|}
\hline Property & Rating & Quality Criteria \\
\hline \multicolumn{3}{|l|}{ Reliability } \\
\hline \multirow[t]{3}{*}{ Internal consistency } & + & (Sub)scale unidimensional AND Cronbach's alpha(s) $\geq 0.70$ \\
\hline & $?$ & Dimensionality not known OR Cronbach's alpha not determined \\
\hline & - & (Sub)scale not unidimensional OR Cronbach's alpha(s) $<0.70$ \\
\hline \multirow[t]{3}{*}{ Measurement error } & + & MIC > SDC OR MIC outside the LOA \\
\hline & $?$ & MIC not defined \\
\hline & - & MIC $\leq$ SDC OR MIC equals or inside LOA \\
\hline \multirow[t]{3}{*}{ Reliability } & + & ICC/weighted Kappa $\geq 0.70$ OR Pearson's $r \geq 0.80$ \\
\hline & $?$ & Neither ICC/weighted Kappa, nor Pearson's r determined \\
\hline & - & ICC/weighted Kappa $<0.70$ OR Pearson's $r<0.80$ \\
\hline \multicolumn{3}{|l|}{ Validity } \\
\hline \multirow[t]{3}{*}{ Content validity } & + & $\begin{array}{l}\text { The target population considers all items in the questionnaire to be relevant } \\
\text { AND considers the questionnaire to be complete }\end{array}$ \\
\hline & $?$ & No target population involvement \\
\hline & - & $\begin{array}{l}\text { The target population considers items in the questionnaire to be irrelevant } \\
\text { OR considers the questionnaire to be incomplete }\end{array}$ \\
\hline \multicolumn{3}{|l|}{ Construct validity } \\
\hline \multirow[t]{3}{*}{ - Cross-cultural validity } & + & Original factor structure confirmed OR no important DIF \\
\hline & $?$ & Confirmation original factor structure AND DIF not mentioned \\
\hline & - & Original factor structure not confirmed OR important DIF \\
\hline \multirow[t]{3}{*}{ - Structural validity } & + & Factors should explain at least $50 \%$ of the variance \\
\hline & $?$ & Explained variance not mentioned \\
\hline & - & Factors explain $<50 \%$ of the variance \\
\hline \multirow[t]{3}{*}{ - Hypothesis testing } & + & $\begin{array}{l}\text { (Correlation with an instrument measuring the same construct } \geq 0.50 \text { OR } \\
\text { at least } 75 \% \text { of the results are in accordance with the hypotheses) AND } \\
\text { correlation with related constructs is higher than with unrelated constructs }\end{array}$ \\
\hline & $?$ & Solely correlations determined with unrelated constructs \\
\hline & - & $\begin{array}{l}\text { Correlation with an instrument measuring the same construct }<0.50 \mathrm{OR} \\
<75 \% \text { of the results are in accordance with the hypotheses OR } \\
\text { correlation with related constructs is lower than with unrelated constructs }\end{array}$ \\
\hline \multicolumn{3}{|l|}{ Responsiveness } \\
\hline \multirow[t]{5}{*}{ Responsiveness } & + & (Correlation with an instrument measuring the same construct $\geq 0.50$ \\
\hline & & OR at least $75 \%$ of the results are in accordance with the hypotheses \\
\hline & & $\begin{array}{l}\text { OR AUC } \geq 0.70 \text { ) AND correlation with related constructs is higher } \\
\text { than with unrelated constructs }\end{array}$ \\
\hline & $?$ & Solely correlations determined with unrelated constructs \\
\hline & - & $\begin{array}{l}\text { Correlation with an instrument measuring the same construct }<0.50 \text { OR } \\
<75 \% \text { of the results are in accordance with the hypotheses OR AUC }<0.70 \\
\text { OR correlation with related constructs is lower than with unrelated constructs }\end{array}$ \\
\hline
\end{tabular}

[.. $]=$ reference number, MIC = minimal important change, SDC = smallest detectable change, $\mathrm{LOA}=$ limits of agreement, ICC = intraclass correlation coefficient, $\mathrm{DIF}=$ differential item functioning, $\mathrm{AUC}=$ area under the curve

${ }^{\dagger}+=$ positive rating, ? = indeterminate rating, $-=$ negative rating

The available information on measurement properties of the Chinese NPQ looks promising, despite the poor methodological quality of the translation process.

\section{Dutch}

The NDI, NPDS, and Neck Bournemouth Questionnaire (NBQ) have been translated in Dutch [19,29-31]. The NPDS was originally designed to measure pain and disability in patients with neck pain [2]. The NBQ was originally designed to measure pain, physical functioning, social functioning, and psychological functioning in patients with non-specific neck pain [32]. The translation process of the NDI is not described, so the quality of this process is unknown. The methodological quality of the translation process of the NDPS is fair, [19] and of the NBQ is excellent [30].

There is limited positive evidence for the reliability of the NDI (ICC = 0.90), [31] and for responsiveness 


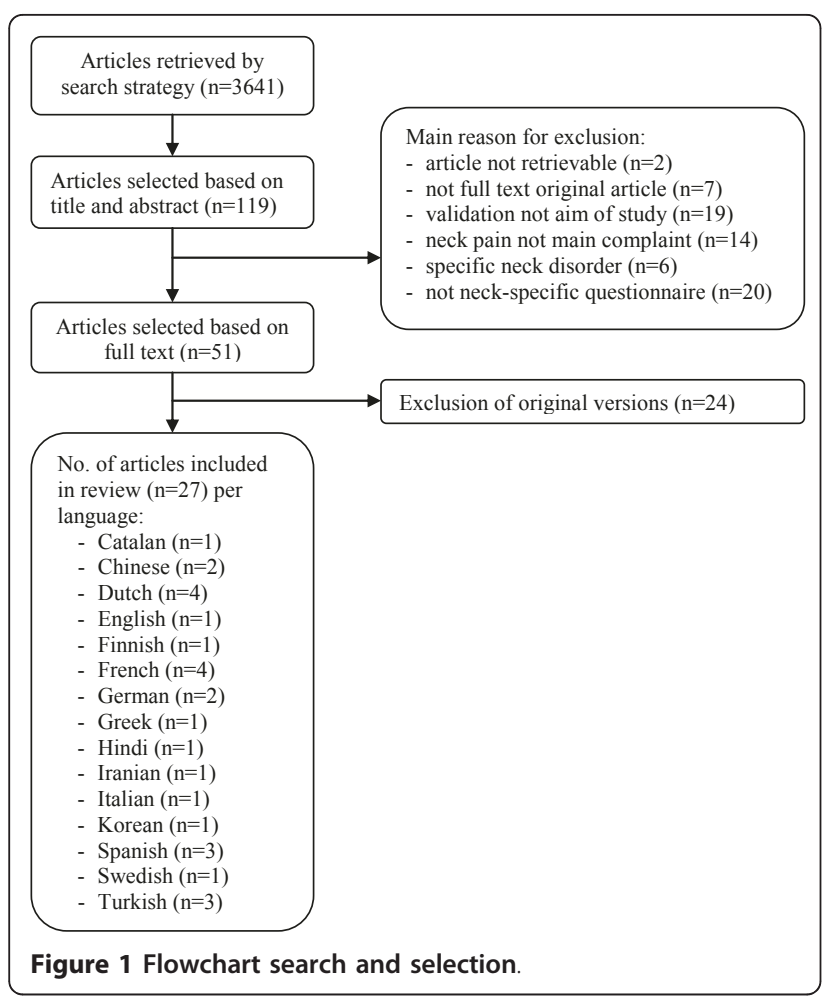

(sensitivity $=0.9$ and specificity $=0.7$ for a clinically important change of 3.5) [29]. There is limited negative evidence for its measurement error $(\mathrm{MIC}=3.5$ and $\mathrm{SDC}=$ 10.5 on a $0-50$ scale) [29]. There is limited positive evidence for the reliability of the NBQ $(\mathrm{ICC}=0.92)$ [30]. The result for measurement error of the NBQ is indeterminate, because the MIC is not defined [30]. No floor or ceiling effects have been detected for the NDI or NBQ, and for both questionnaires differences in score between subgroups have been reported (men vs. women) [30,31].

The lack of information derived from these studies makes it difficult to point out the best available neck-specific questionnaire in Dutch. Based on the information available on the measurement properties of the original version of the NDI and NBQ, we advise to use the Dutch NDI. (Schellingerhout JM, Heymans MW, Verhagen AP, De Vet HC, Koes BW, Terwee CB: Measurement properties of disease-specific questionnaires in patients with neck pain: a systematic review, submitted)

\section{English}

The, originally Danish, Copenhagen Neck Functional Disability Scale (CNFDS) is the only neck-specific

Table 4 General information per study

\begin{tabular}{|c|c|c|c|c|}
\hline Study & Language & Country & Population & Setting \\
\hline Nieto et al. [25] & Catalan & Spain & $<3$ months whiplash & rehabilitation unit \\
\hline Chiu et al. [26] & Chinese & Hong Kong & neck pain & physiotherapist \\
\hline Lee et al. [27] & Chinese & Hong Kong & neck pain & physiotherapist \\
\hline Jorritsma et al. [19] & Dutch & Netherlands & $>3$ months non-specific neck pain & rehabilitation unit \\
\hline Pool et al. [29] & Dutch & Netherlands & non-specific neck pain & general practitioner \\
\hline Schmitt et al. [30] & Dutch & Netherlands & $>3$ weeks whiplash & general population \\
\hline Vos et al. [31] & Dutch & Netherlands & $<6$ weeks non-specific neck pain & general practitioner \\
\hline Stewart et al. [33] & English & Australia & $>3$ months whiplash & physiotherapist \\
\hline Salo et al. [35] & Finnish & Finland & neck pain & physiotherapist/rehabilitation unit \\
\hline Forestier et al. [18] & French & France & $>3$ months mechanical neck pain & general population \\
\hline Martel et al. [37] & French & Canada & $>12$ weeks mechanical neck pain & general population \\
\hline Wlodyka-Demaille et al. [36] & French & France & > 15 days non-specific neck pain & rehabilitation unit/rheumatologist \\
\hline Wlodyka-Demaille et al. [20] & French & France & $>15$ days non-specific neck pain & rehabilitation unit/rheumatologist \\
\hline Bremerich et al. [24] & German & Switzerland & $>3$ months non-specific neck pain & rheumatologist \\
\hline Scherer et al. [38] & German & Germany & neck pain & general practitioner \\
\hline Trouli et al. [39] & Greek & Greece & non-specific neck pain & primary care \\
\hline Agarwal et al. [40] & Hindi & India & cervical radiculopathy & physiotherapist \\
\hline Mousavi et al. [41] & Iranian & Iran & non-specific neck pain & primary care/physiotherapist \\
\hline Monticone et al. [42] & Italian & Italy & $>4$ weeks non-specific neck pain & rehabilitation unit \\
\hline Lee et al. [43] & Korean & South Korea & non-specific neck pain & physiotherapist \\
\hline Andrade et al. [46] & Spanish & Spain & non-specific neck pain & rehabilitation unit \\
\hline Gonzalez et al. [44] & Spanish & Spain & $>4$ months non-specific neck pain & physiotherapist \\
\hline Kovacs et al. [23] & Spanish & Spain & non-specific neck pain & primary care/hospital outpatient clinic \\
\hline Ackelman et al. [22] & Swedish & Sweden & acute/chronic neck pain & emergency room/physiotherapist \\
\hline Aslan et al. [47] & Turkish & Turkey & $>3$ months non-specific neck pain & physiotherapist/rehabilitation unit \\
\hline Bicer et al. [21] & Turkish & Turkey & $>6$ months non-specific neck pain & rehabilitation unit \\
\hline Kose et al. [48] & Turkish & Turkey & > 6 weeks non-specific neck pain & primary care \\
\hline
\end{tabular}

$[.]=$. reference number 
Table 5 Methodological quality of each study per measurement property

\begin{tabular}{|c|c|c|c|c|c|c|c|c|c|}
\hline $\begin{array}{l}\text { Language } \\
\text { Study }\end{array}$ & Instrument & $\begin{array}{c}\text { Translation } \\
\text { process }\end{array}$ & $\begin{array}{c}\text { Internal } \\
\text { Consistency }\end{array}$ & $\begin{array}{c}\text { Measurement } \\
\text { Error }\end{array}$ & Reliability & $\begin{array}{l}\text { Content } \\
\text { Validity }\end{array}$ & $\begin{array}{c}\text { Structural } \\
\text { Validity }\end{array}$ & $\begin{array}{c}\text { Hypotheses } \\
\text { Testing }\end{array}$ & Responsiveness \\
\hline \multicolumn{10}{|l|}{ Catalan } \\
\hline Nieto et al. [25] & $\mathrm{NDI}$ & poor & good & & & & fair & good & \\
\hline \multicolumn{10}{|l|}{ Chinese } \\
\hline Chiu et al. [26] & NPQ & poor & poor & & excellent & poor & & fair & poor \\
\hline Lee et al. [27] & NPQ & & & & & & & fair & poor \\
\hline \multicolumn{10}{|l|}{ Dutch } \\
\hline \multirow[t]{2}{*}{ Jorritsma et al. [19] } & NDI & & & poor & poor & & & & \\
\hline & NPDS & fair & & poor & poor & & & & \\
\hline Pool et al. [29] & NDI & & & fair & & & & & fair \\
\hline Schmitt et al. [30] & NBQ & excellent & poor & fair & fair & & & poor & \\
\hline Vos et al. [31] & $\mathrm{NDI}$ & & & fair & fair & & & & poor \\
\hline \multicolumn{10}{|l|}{ English } \\
\hline Stewart et al. [33] & CNFDS & & & & & & & & fair \\
\hline \multicolumn{10}{|l|}{ Finnish } \\
\hline \multirow[t]{2}{*}{ Salo et al. [35] } & NDI & poor & excellent & & poor & & good & poor & \\
\hline & NPDS & poor & excellent & & poor & & good & poor & \\
\hline \multicolumn{10}{|l|}{ French } \\
\hline Forestier et al. [18] & CNFDS & poor & poor & & & & & & poor \\
\hline Martel et al. [37] & NBQ & poor & & & poor & & & fair & moderate \\
\hline \multirow[t]{3}{*}{ Wlodyka et al. [36] } & NDI & poor & poor & poor & poor & & fair & fair & \\
\hline & NPDS & poor & poor & poor & poor & & fair & fair & \\
\hline & NPQ & poor & poor & poor & poor & & fair & fair & \\
\hline \multirow[t]{3}{*}{ Wlodyka et al. [20] } & NDI & & & & & & & & poor \\
\hline & NPDS & & & & & & & & poor \\
\hline & NPQ & & & & & & & & poor \\
\hline \multicolumn{10}{|l|}{ German } \\
\hline Bremerich et al. [24] & NPDS & fair & & poor & poor & & & & \\
\hline Scherer et al. [38] & NPDS & poor & excellent & & & & good & good & \\
\hline \multicolumn{10}{|l|}{ Greek } \\
\hline Trouli et al. [39] & $\mathrm{NDI}$ & good & good & poor & poor & & good & & fair \\
\hline \multicolumn{10}{|l|}{ Hindi } \\
\hline Agarwal et al. [40] & NPDS & fair & poor & poor & poor & poor & & fair & \\
\hline \multicolumn{10}{|l|}{ Iranian } \\
\hline \multirow[t]{2}{*}{ Mousavi et al. [41] } & $\mathrm{NDI}$ & excellent & fair & & fair & poor & & & fair \\
\hline & NPDS & excellent & fair & & fair & poor & fair & & fair \\
\hline \multicolumn{10}{|l|}{ Italian } \\
\hline Monticone et al. [42] & NPDS & poor & fair & & fair & & fair & poor & \\
\hline \multicolumn{10}{|l|}{ Korean } \\
\hline \multirow[t]{2}{*}{ Lee et al. [43] } & NDI & poor & fair & poor & poor & & & fair & poor \\
\hline & NPDS & poor & poor & poor & poor & & & fair & poor \\
\hline \multicolumn{10}{|l|}{ Spanish } \\
\hline Andrade et al. [46] & NDI & & fair & poor & poor & & fair & fair & fair \\
\hline Gonzalez et al. [44] & $N P Q$ & poor & poor & & fair & & & poor & poor \\
\hline Kovacs et al. [23] & NDI & excellent & poor & & poor & & & poor & poor \\
\hline & NPQ & & poor & & & & & poor & poor \\
\hline & CNQ & excellent & poor & & poor & & & poor & poor \\
\hline Swedish & & & & & & & & & \\
\hline Ackelman et al. [22] & $\mathrm{NDI}$ & & & & poor & poor & & poor & \\
\hline Turkish & & & & & & & & & \\
\hline Aslan et al. [47] & $\mathrm{NDI}$ & excellent & & & fair & & & fair & \\
\hline
\end{tabular}


Table 5 Methodological quality of each study per measurement property (Continued)

\begin{tabular}{|c|c|c|c|c|c|c|}
\hline Bicer et al. [21] & NPDS & poor & poor & & poor & \\
\hline \multirow[t]{4}{*}{ Kose et al. [48] } & NDI & fair & poor & fair & poor & fair \\
\hline & NPDS & fair & poor & fair & poor & fair \\
\hline & NPQ & fair & poor & fair & poor & fair \\
\hline & CNFDS & fair & poor & fair & poor & fair \\
\hline
\end{tabular}

$[.]=$. reference number

questionnaire that has been translated in English [33]. The CNFDS was originally designed to measure disability in patients with neck pain [34]. The translation process is not described, so the quality of this process is unknown. There is limited positive evidence for the responsiveness of the CNFDS (AUC $=0.73$ ) [33]. Many neck-specific questionnaires have originally been developed in English. We advise to use one of these questionnaires, preferably the NDI. (Schellingerhout JM,
Heymans MW, Verhagen AP, De Vet HC, Koes BW, Terwee CB: Measurement properties of disease-specific questionnaires in patients with neck pain: a systematic review, submitted)

\section{Finnish}

The NDI and NPDS have been translated in Finnish [35]. The methodological quality of the translation process of these questionnaires is poor [35].

Table 6 Quality of the measurement properties per language and questionnaire

\begin{tabular}{|c|c|c|c|c|c|c|c|c|c|c|c|}
\hline \multirow[t]{2}{*}{ Language } & \multirow[t]{2}{*}{ Instrument } & \multirow[t]{2}{*}{$\begin{array}{c}\text { Internal } \\
\text { Consistency }\end{array}$} & \multirow[t]{2}{*}{$\begin{array}{c}\text { Measurement } \\
\text { Error }\end{array}$} & \multirow[t]{2}{*}{ Reliability } & \multirow[t]{2}{*}{$\begin{array}{l}\text { Content } \\
\text { Validity }\end{array}$} & \multicolumn{4}{|c|}{$\begin{array}{l}\text { Structural } \\
\text { Validity }^{\dagger}\end{array}$} & \multirow[t]{2}{*}{$\begin{array}{l}\text { Hypotheses } \\
\text { Testing }\end{array}$} & \multirow[t]{2}{*}{ Responsiveness } \\
\hline & & & & & & 1 & 2 & 3 & 4 & & \\
\hline Catalan & $\mathrm{NDI}$ & ++ & na & na & na & - & + & & & ++ & na \\
\hline Chinese & NPQ & $?$ & na & +++ & $?$ & na & & & & ++ & $?$ \\
\hline \multirow[t]{3}{*}{ Dutch } & $\mathrm{NDI}$ & na & - & + & na & na & & & & na & + \\
\hline & NPDS & na & $?$ & $?$ & na & na & & & & na & na \\
\hline & NBQ & $?$ & $?$ & + & na & na & & & & $?$ & na \\
\hline English & CNFDS & na & na & na & na & na & & & & na & + \\
\hline \multirow[t]{2}{*}{ Finnish } & NDI & $?$ & na & $?$ & na & - & & & & $?$ & na \\
\hline & NPDS & +++ & na & $?$ & na & & & ++ & & $?$ & na \\
\hline \multirow[t]{5}{*}{ French } & NDI & na & $?$ & $?$ & na & & + & & & - & $?$ \\
\hline & NPDS & na & $?$ & $?$ & na & & & + & & $+/-$ & $?$ \\
\hline & NBQ & na & na & $?$ & na & na & & & & $+/-$ & - \\
\hline & NPQ & na & $?$ & $?$ & na & & + & & & $+/-$ & $?$ \\
\hline & CNFDS & $?$ & na & na & na & na & & & & na & $?$ \\
\hline German & NPDS & $?$ & $?$ & $?$ & na & - & & ++ & & ++ & na \\
\hline Greek & $\mathrm{NDI}$ & $?$ & $?$ & $?$ & na & - & & & & na & - \\
\hline Hindi & NPDS & $?$ & $?$ & $?$ & $?$ & na & & & & $+/-$ & na \\
\hline \multirow[t]{2}{*}{ Iranian } & NDI & + & na & + & $?$ & na & & & & na & + \\
\hline & NPDS & + & na & + & $?$ & & & & + & na & - \\
\hline Italian & NPDS & + & na & + & na & & & + & & $?$ & na \\
\hline \multirow[t]{2}{*}{ Korean } & NDI & + & $?$ & $?$ & na & na & & & & $?$ & $?$ \\
\hline & NPDS & $?$ & $?$ & $?$ & na & na & & & & $?$ & $?$ \\
\hline \multirow[t]{3}{*}{ Spanish } & $\mathrm{NDI}$ & + & na & $?$ & na & + & & & & + & + \\
\hline & NPQ & $?$ & na & - & na & na & & & & $?$ & $?$ \\
\hline & CNQ & $?$ & na & $?$ & na & na & & & & $?$ & $?$ \\
\hline Swedish & $\mathrm{NDI}$ & na & na & $?$ & $?$ & na & & & & $?$ & na \\
\hline \multirow[t]{4}{*}{ Turkish } & $\mathrm{NDI}$ & $?$ & na & ++ & na & na & & & & + & + \\
\hline & NPDS & $?$ & na & + & na & na & & & & $?$ & + \\
\hline & NPQ & $?$ & na & + & na & na & & & & $?$ & + \\
\hline & CNFDS & $?$ & na & + & na & na & & & & $?$ & + \\
\hline
\end{tabular}

+++ or $-=$ strong evidence positive/negative result, ++ or $-=$ moderate evidence positive/negative result, + or $-=$ limited evidence positive/negative result, $+/-$ $=$ conflicting evidence, $?=$ unknown, due to poor methodological quality, na = no information available

${ }^{\dagger}$ the numbers reflect the number of factors that are mentioned in the underlying studies 
There is moderate evidence that the NDI is not onedimensional and that the NPDS has a 3-factor structure [35]. The result for internal consistency of the NDI is indeterminate, because the authors unjustly assume a 1factor model [35]. There is strong positive evidence for the internal consistency of the NPDS (Cronbach $\alpha=$ 0.82-0.84) [35]. No floor or ceiling effects have been detected for the NDI or NPDS and for both questionnaires differences in score between subgroups have been reported (stable vs. improved patients) [35].

The available information suggests that the Finnish NPDS has better measurement properties than the Finnish NDI.

\section{French}

The following neck-specific questionnaires have been translated in French: NDI, [20,36] NPDS, [20,36] NBQ, [37] NPQ, [20,36] and CNFDS [18]. The methodological quality of all these translation processes is poor $[18,36,37]$.

There is limited evidence that the NDI has a 2-factor structure [20]. Hypothesis testing showed that the correlation of the NDI with an instrument measuring psychological functioning is somewhat higher $(r=0.55)$, than with instruments measuring pain $(r=0.48)$, and physical functioning $(r=0.50)$ [20]. There is limited evidence that the NPDS has a 3-factor structure [20]. Hypothesis testing showed a positive result for correlation of the NPDS with instruments measuring pain $(r=0.52)$, and physical functioning $(r=0.63)$, and a negative result (results slightly below the pre-set criterion of $\mathrm{r}=0.5$ ) for correlation with instruments measuring psychological functioning $(\mathrm{r}=0.40-0.49)$ [20]. Hypothesis testing showed a positive result for correlation of the NBQ with an instrument measuring pain and physical functioning $(r=0.61-0.67)$, and a negative result for correlation with an instrument measuring psychological functioning $(\mathrm{r}=$ $0.17-0.25$ ) [37]. There is limited negative evidence for the responsiveness of the NBQ $(r=0.42)$ [37]. There is limited evidence that the NPQ has a 2-factor structure [20]. Hypothesis testing showed a positive result for correlation of the NPQ with an instrument measuring physical functioning $(r=0.53)$, and a negative result for correlation with an instrument measuring pain $(\mathrm{r}=$ 0.43) [20].

No floor or ceiling effects have been detected for the NDI, NPDS, and NPQ [20,36]. The average time needed to fill out the NDI, NPDS, and NPQ is 7.4, 6.4, and 7.2 minutes, respectively [36].

The lack of information derived from these studies makes it difficult to point out the best available neckspecific questionnaire in French. Based on the information available on the measurement properties of the original version of the NDI, NPDS, NBQ, NPQ, and
CNFDS, we advise to develop a high quality translation of the NDI. (Schellingerhout JM, Heymans MW, Verhagen AP, De Vet HC, Koes BW, Terwee CB: Measurement properties of disease-specific questionnaires in patients with neck pain: a systematic review, submitted)

\section{German}

The NPDS is the only neck-specific questionnaire that has been translated in German [24,38]. There are two translations of the NPDS in German: one translation process of poor and one of fair methodological quality [24,38].

Factor analysis provided moderate evidence that the NPDS has a 3-factor structure [38]. The result for internal consistency is indeterminate, [38] because the authors unjustly assume a 1-factor model. There is moderate positive evidence for hypothesis testing ( $>75 \%$ of results in accordance with predefined hypotheses) [38]. No floor or ceiling effects have been detected for the NPDS [38].

The available information on measurement properties of the German NPDS looks promising, despite the poor methodological quality of the translation process.

\section{Greek}

The NDI is the only neck-specific questionnaire that has been translated in Greek [39]. The methodological quality of the translation process is good [39].

Exploratory factor analysis provided moderate evidence that the NDI does not have a 1-factor structure [39]. The result for internal consistency is indeterminate, [39] because the authors unjustly assume a 1-factor model. There is limited negative evidence for responsiveness ( $r=0.30$ with Global Rating of Change) [39].

Based on the good quality of the translation process and the negative results for unidimensionality and responsiveness, we advise to perform a cross-cultural validation of the Greek NDI.

\section{Hindi}

The NPDS is the only neck-specific questionnaire that has been translated in Hindi [40]. The methodological quality of the translation process is fair [40].

Hypothesis testing showed a positive result for correlation of the NPDS with an instrument measuring psychological functioning $(r=0.80)$, and a negative result for correlation with an instrument measuring pain $(\mathrm{r}=$ 0.30 ), and an instrument measuring physical functioning $(\mathrm{r}=0.15)$. The average time needed to fill out the NPDS was 8 minutes [40].

Based on the information derived from this study, we advise to develop a high quality translation of the NDI. 


\section{Iranian}

The NDI and NPDS have been translated in Iranian [41]. The methodological quality of the translations processes is excellent [41].

There is limited positive evidence for the internal consistency (Cronbach alpha $=0.88$, assuming a 1 -factor structure), reliability (ICC $=0.97$ ), and responsiveness $(r=0.65$ for physical functioning and $r=0.70$ for pain) of the NDI [41]. Exploratory factor analysis resulted in limited positive evidence for a 4-factor structure of the NPDS [41]. There is limited positive evidence for internal consistency (Cronbach alpha = $0.75-0.94$ for the four subscales), and reliability (ICC = 0.97) [41]. There is limited negative evidence for responsiveness of the NPDS, because correlation with change scores on instruments measuring the same constructs was lower than correlation with instruments measuring other constructs [41]. No floor or ceiling effects have been detected for the NDI or NPDS [41].

The Iranian NDI and NPDS both seem to have adequate measurement properties, but we advise using the NDI, based on the negative result for responsiveness of the NPDS and the good measurement properties of the original version of the NDI. (Schellingerhout JM, Heymans MW, Verhagen AP, De Vet HC, Koes BW, Terwee $C B$ : Measurement properties of disease-specific questionnaires in patients with neck pain: a systematic review, submitted)

\section{Italian}

The NPDS is the only neck-specific questionnaire that has been translated in Italian [42]. The methodological quality of the translation process is poor [42].

There is limited evidence that the NPDS has a 3-factor structure (variance $=63 \%$ ) [42]. A confirmatory analysis with 4 factors showed a small improvement in variance (67\%) [42]. Assuming a 3-factor structure, there is limited positive evidence for internal consistency: Cronbach $\alpha$ was 0.92 for "neck dysfunction related to general activities", 0.86 for "cognitive-behavioral aspects", and 0.89 for "neck dysfunction related to activities of the cervical spine" [42]. There is limited positive evidence for the reliability of the NPDS ( $r=$ 0.89-0.93) [42]. The average time needed to fill out the NPDS is 7.5 minutes [42].

The available information on measurement properties of the Italian NPDS looks promising, despite the poor methodological quality of the translation.

\section{Korean}

The NDI and NPDS have been translated in Korean [43]. The methodological quality of the translation processes is poor [43].
There is limited positive evidence regarding the internal consistency of the NDI (Cronbach $\alpha=0.92$, assuming a 1-factor structure) [43]. No floor or ceiling effects have been detected for the NDI or NPDS and differences in score between subgroups have been reported (neck pain patients vs. healthy persons) [43].

Lack of information makes it difficult to point out whether the Korean NDI or NPDS has the best measurement properties. Based on the information available on the measurement properties of the original version of the NDI and NPDS, we advise to use the Korean NDI. (Schellingerhout JM, Heymans MW, Verhagen AP, De Vet HC, Koes BW, Terwee CB: Measurement properties of disease-specific questionnaires in patients with neck pain: a systematic review, submitted)

\section{Spanish}

The NDI, NPQ, and Core Neck Questionnaire (CNQ) have been translated in Spanish [23,44]. The CNQ was originally designed to measure outcomes of care in patients with non-specific neck pain [45]. The methodological quality of the translation process of the NPQ is poor, [44] and of the NDI and CNQ is excellent [23].

There is limited positive evidence for a 1-factor structure of the NDI and its internal consistency (Cronbach $\alpha=0.89$ ) [46]. Hypothesis testing showed a positive result for correlation of the NDI with an instrument measuring pain $(\mathrm{r}=0.65)$, and an instrument measuring physical functioning $(r=0.89)$ [46]. There is limited positive evidence for the responsiveness of the NDI [46]. There is limited negative evidence regarding the reliability of the NPQ (ICC = 0.63) [44]. No floor or ceiling effects have been detected for the NDI, NPQ, or CNQ, and scores across different categories of pain intensity have been reported [23]. The average time needed to fill out the NDI and CNQ is 4.0 and 2.1 minutes, respectively [23].

Based on the available information, we advise to use the Spanish NDI.

\section{Swedish}

The NDI is the only neck-specific questionnaire that has been translated in Swedish [22]. The methodological quality of the translation process is unknown. No floor or ceiling effects have been detected for the NDI [22].

Based on the lack of information, we advise to perform high quality studies to fill in the missing information on the measurement properties of the Swedish NDI.

\section{Turkish}

The following neck-specific questionnaires have been translated and evaluated in Turkish: NDI, $[47,48]$ NPDS, $[21,48]$ NPQ, [48] and CNFDS [48]. There are two 
translations of the NDI in Turkish: one translation process was of excellent methodological quality, [47] and one of fair methodological quality [48]. There are two translations of the NPDS as well: one translation process was of poor methodological quality, [21] and one of fair methodological quality [48]. The translation processes of the NPQ and CNFDS are both of fair methodological quality [48].

There is moderate positive evidence for the reliability of the NDI (ICC $=0.86-0.98)$, $[47,48]$ and limited positive evidence for hypothesis testing $(r=0.66-0.73$ with instruments measuring pain and/or disability) and responsiveness $(r=0.79$, with a physician's assessment of health) $[47,48]$. There is limited positive evidence for the reliability $\left(\mathrm{ICC}_{\mathrm{NPDS}}=0.81, \mathrm{ICC}_{\mathrm{NPQ}}=0.85\right.$, $\left.\mathrm{ICC}_{\mathrm{CNFDS}}=0.84\right)$ and responsiveness $\left(\mathrm{r}_{\mathrm{NPDS}}=0.79\right.$, $\mathrm{r}_{\mathrm{NPQ}}=0.81$, and $\mathrm{r}_{\mathrm{CNFDS}}=0.65$, with a physician's assessment of health on a scale of 0 to 100) of the NPDS, NPQ, and CNFDS [48].

The average time needed to fill out the NDI, NPDS, $\mathrm{NPQ}$, and CNFDS is $8.8,10.2,8.4$, and 6.8 minutes, respectively [48]. All 4 translated questionnaires show promising results, but we advise using the NDI, because of the excellent methodological quality of the translation process and the good measurement properties of the original version. (Schellingerhout JM, Heymans MW, Verhagen AP, De Vet HC, Koes BW, Terwee CB: Measurement properties of disease-specific questionnaires in patients with neck pain: a systematic review, submitted)

\section{Discussion}

Translated versions of neck-specific questionnaires have been evaluated in 15 different languages. Generally the methodological quality of the translation process is poor, which was mainly due to the fact that the translated version was not pre-tested in the target population. Furthermore, none of the included studies performed a cross-cultural validation. This is necessary to evaluate whether the constructs underlying the original questionnaire are represented adequately by the questionnaire items in the new language. For each questionnaire, except for the Iranian NPDS and Spanish NDI, at least half of the information regarding measurement properties was lacking. Moreover, the evidence for the quality of measurement properties of the translated versions is mostly limited, due to methodological shortcomings of the included studies.

The COSMIN checklist has recently been developed and is based on consensus between experts in the field of health status questionnaires [9]. The COSMIN checklist facilitates a separate judgment of the methodological quality of the included studies and their results. This is in line with the methodology of systematic reviews of clinical trials [15]. The criteria in Table 2 are based on the levels of evidence as previously proposed by the Cochrane Back Review Group [16]. The criteria are originally meant for systematic reviews of clinical trials, but we believe that they are also applicable for reviews on measurement properties of health status questionnaires.

Exclusion of non-English papers may introduce selection bias. However, the leading journals, and as a consequence the most important studies, are published in English. So, research performed in populations with a different native language is generally still published in English. This is illustrated by the large number of articles we retrieved regarding translations of neck-specific questionnaires (see Figure 1). Thus, we argue that the most important translations have been included in our study.

Many studies showed similar methodological shortcomings. Some methodological aspects that need to be improved are: assessment of unidimensionality in internal consistency analysis, the use of stable patients and similar test conditions in studies on reliability and measurement error, and studies on construct validity and responsiveness should be based on predefined hypotheses. We do not discuss these flaws here, because we have elaborated on this subject in a separate paper. (Terwee CB, Schellingerhout JM, Verhagen AP, de Vet HC, Koes BW: Assessing the measurement properties of neck disability questionnaires: room for improvement, submitted)

We pooled the results per language, which neglects the fact that populations might share the same language, but differ in cultural context [3]. However, we think that this did not affect our results, because the only inconsistency in results for the same language version was found for the Chinese NPQ and the populations in the two studies evaluating the Chinese NPQ came from the same region in China and were similar in context $[26,27]$.

A systematic review of the measurement properties of the original version of neck-specific questionnaires showed that for each questionnaire, except for the NDI, at least half of the information regarding measurement properties was lacking. The available results were mainly positive, but the evidence was mostly limited. (Schellingerhout JM, Heymans MW, Verhagen AP, De Vet HC, Koes BW, Terwee CB: Measurement properties of disease-specific questionnaires in patients with neck pain: a systematic review, submitted) This systematic review of translated questionnaires shows similar findings, except that the results for construct validity and responsiveness are more frequently inconsistent or negative. These inconsistencies are in correspondence with those found for translations of the McGill Pain Questionnaire [7]. A possible explanation for this difference in results between original questionnaires and their translated 
counterparts is the poor methodological quality of the translation process and/or lack of cross-cultural validation $[3,4]$.

A poor translation process and/or lack of cross-cultural validation seem to primarily affect the validity of the questionnaire. This is illustrated by the differences found between the results for structural validity of the translated versions and their original counterparts, and the negative/inconsistent results for hypothesis testing of the translated questionnaires. This is not surprising, as the importance and/or meaning of questionnaire items (e.g. driving, depressed mood) may depend on setting and context. So, a simple translation of the original questionnaire is not sufficient and might affect the underlying constructs. The translation process does not seem to affect the reliability of the questionnaire. This is illustrated by the fact that $95 \%$ of the results for internal consistency and reliability are positive, regardless of the methodological quality of the translation process.

A recent review concluded that the translated versions of the NDI into Brazilian-Portuguese, Dutch, French, Korean, and Spanish are of high quality [6]. A possible explanation for discrepancies with our findings is that the methodological quality of the translation process was not taken into account in that review. The same accounts for a state-of-the-art review of the NDI, in which a list of available translations is recommended, without critical appraisal of the quality of the translation process and cross-cultural validation, nor the quality of the measurement properties [5].

This study evaluates the measurement properties of translated versions of neck-specific questionnaires, thereby providing an overview of their availability and making it possible to choose the best questionnaire for a specific study population. However, it is advisable to use them cautiously, since the evidence is mostly limited and for each of these translations, except for the Spanish NDI, at least half of the information regarding measurement properties is lacking. For clinical research and practice we advise to use the following questionnaires: the Catalan, Dutch, English, Iranian, Korean, Spanish and Turkish version of the NDI, the Chinese version of the NPQ, and the Finnish, German and Italian version of the NPDS. This is based on the available results for the measurement properties of these translations, and in the case of the Dutch, English, and Korean NDI on the measurement properties of the original version. (Schellingerhout JM, Heymans MW, Verhagen AP, De Vet HC, Koes BW, Terwee CB: Measurement properties of disease-specific questionnaires in patients with neck pain: a systematic review, submitted) The Greek NDI needs cross-cultural validation and due to poor methodological quality of the available study there is no information on the Swedish
NDI. For all other languages it is advisable to first choose the best available original version of the neckspecific questionnaires and perform a high quality translation of this questionnaire. Our previous systematic review on the original versions of all neck-specific questionnaires showed that the NDI was the best questionnaire. (Schellingerhout JM, Heymans MW, Verhagen AP, De Vet HC, Koes BW, Terwee CB: Measurement properties of disease-specific questionnaires in patients with neck pain: a systematic review, submitted)

For future research we recommend performing high quality studies to fill in the information on the unknown measurement properties.

\section{Conclusion}

Translated versions of neck-specific questionnaires have been evaluated in 15 different languages. Generally the methodological quality of the translation process is poor and none of the included studies performed a cross-cultural validation. A substantial amount of information regarding the measurement properties of translated versions of the different neck-specific questionnaires is still lacking or assessed in studies of poor methodological quality. As a result the available evidence on the measurement properties is mostly limited. So, it is advisable to use the available translated questionnaires cautiously. For the time being we advise to use the following questionnaires in clinical research and practice: the Catalan, Dutch, English, Iranian, Korean, Spanish and Turkish version of the NDI, the Chinese version of the NPQ, and the Finnish, German and Italian version of the NPDS. The Greek NDI needs cross-cultural validation and there is no methodologically sound information for the Swedish NDI. Studies of high methodological quality are needed to fill in the unknown measurement properties.

For all other languages we advise to translate the original version of the NDI.

\section{Author details \\ 'Department of General Practice, Erasmus Medical Centre, Rotterdam, The Netherlands. ${ }^{2}$ Department of Epidemiology and Biostatistics, EMGO Institute for Health and Care Research, VU University Medical Centre, Amsterdam, The Netherlands. ${ }^{3}$ Department of Methodology and Applied Biostatistics, VU University Medical Centre, Amsterdam, The Netherlands.}

\section{Authors' contributions}

JMS carried out the bibliographic search, data extraction and assessment of (methodological) quality, and drafted the manuscript. MWH revised the manuscript. APV carried out the bibliographic search and revised the manuscript. HCV was involved in the bibliographic search, data extraction and assessment of (methodological) quality, and revised the manuscript. BWK revised the manuscript. CBT carried out the data extraction and assessment of (methodological) quality, and revised the manuscript. All authors were involved in designing the study. All authors read and approved the final manuscript. 


\section{Competing interests}

The authors declare that they have no competing interests.

Received: 4 March 2011 Accepted: 6 June 2011 Published: 6 June 2011

\section{References}

1. Vernon $\mathrm{H}$, Mior S: The Neck Disability Index: a study of reliability and validity. J Manipulative Physiol Ther 1991, 14:409-415.

2. Wheeler AH, Goolkasian P, Baird AC, Darden BV: Development of the Neck Pain and Disability Scale. Item analysis, face, and criterion-related validity. Spine 1999, 24:1290-1294.

3. Beaton DE, Bombardier C, Guillemin F, Ferraz MB: Guidelines for the process of cross-cultural adaptation of self-report measures. Spine 2000, 25:3186-3191.

4. Wang WL, Lee HL, Fetzer SJ: Challenges and strategies of instrument translation. West I Nurs Res 2006, 28:310-321.

5. Vernon H: The Neck Disability Index: State-of-the-Art, 1991-2008. J Manipulative Physiol Ther 2008, 31:491-502.

6. MacDermid JC, Walton DM, Avery S, Blanchard A, Etruw E, McAlpine C, Goldsmith CH: Measurement properties of the neck disability index: a systematic review. J Orthop Sports Phys Ther 2009, 39:400-417.

7. Menezes da Costa L, Maher CG, McAuley JH, Costa LO: Systematic review of cross-cultural adaptations of McGill Pain Questionnaire reveals a paucity of clinimetric testing. J Clin Epidemiol 2009, 62:934-943.

8. Mokkink LB, Terwee CB, Patrick DL, Alonso J, Stratford PW, Knol DL, Bouter LM, de Vet HC: The COSMIN study reached international consensus on taxonomy, terminology, and definitions of measurement properties for health-related patient-reported outcomes. J Clin Epidemiol 2010, 63:737-745.

9. Mokkink LB, Terwee CB, Patrick DL, Alonso J, Stratford PW, Knol DL, Bouter LM, de Vet HC: The COSMIN checklist for assessing the methodological quality of studies on measurement properties of health status measurement instruments: an international Delphi study. Qua Life Res 2010, 19:539-549.

10. de Vet $\mathrm{HC}$, Terwee $\mathrm{CB}$, Knol DL, Bouter $\mathrm{LM}$ : When to use agreement versus reliability measures. J Clin Epidemiol 2006, 59:1033-1039.

11. Bland JM, Altman DG: Statistical methods for assessing agreement between two methods of clinical measurement. Lancet 1986, 1:307-310.

12. Terwee $C B$, Roorda LD, Knol DL, De Boer MR, De Vet HC: Linking measurement error to minimal important change of patient-reported outcomes. J Clin Epidemiol 2009, 62:1062-1067.

13. Streiner DL, Norman GR: Health measurement scales: a practical guide to their development and use. Oxford: Oxford University Press; 32003.

14. Mokkink LB, Terwee CB, Knol DL, Stratford PW, Alonso J, Patrick DL, Bouter LM, de Vet HC: The COSMIN checklist for evaluating the methodological quality of studies on measurement properties: A clarification of its content. BMC Med Res Methodol 2010, 10:22.

15. Furlan AD, Pennick V, Bombardier C, van Tulder M, Editorial Board CBRG: 2009 updated method guidelines for systematic reviews in the Cochrane Back Review Group. Spine 2009, 34:1929-1941.

16. van Tulder M, Furlan A, Bombardier C, Bouter L, Editorial Board CBRG: Updated method guidelines for systematic reviews in the cochrane collaboration back review group. Spine 2003, 28:1290-1299.

17. Terwee CB, Bot SDM, de Boer MR, van der Windt DAWM, Knol DL, Dekker J, Bouter LM, de Vet HCW: Quality criteria were proposed for measurement properties of health status questionnaires. J Clin Epidemiol 2007, 60:34-42.

18. Forestier R, Francon A, Arroman FS, Bertolino C: French version of the Copenhagen neck functional disability scale. Joint Bone Spine 2007, 74:155-159.

19. Jorritsma W, de Vries GE, Geertzen JH, Dijkstra PU, Reneman MF: Neck Pain and Disability Scale and the Neck Disability Index: reproducibility of the Dutch Language Versions. Eur Spine J 2010, 19:1695-1701.

20. Wlodyka-Demaille S, Poiraudeau S, Catanzariti JF, Rannou F, Fermanian J, Revel M: The ability to change of three questionnaires for neck pain. Joint Bone Spine 2004, 71:317-326.

21. Bicer A, Yazici A, Camdeviren H, Erdogan C: Assessment of pain and disability in patients with chronic neck pain: reliability and construct validity of the Turkish version of the neck pain and disability scale. Disabil Rehabil 2004, 26:959-962.

22. Ackelman BH, Lindgren $U$ : Validity and reliability of a modified version of the neck disability index. J Rehabil Med 2002, 34:284-287.
23. Kovacs FM, Bago J, Royuela A, Seco J, Gimenez S, Muriel A, Abraira V, Martin JL, Pena JL, Gestoso M, et al: Psychometric characteristics of the Spanish version of instruments to measure neck pain disability. BMC Musculoskelet Disord 2008, 9:42.

24. Bremerich FH, Grob D, Dvorak J, Mannion AF: The neck pain and disability scale: Cross-cultural adaptation into german and evaluation of its psychometric properties in chronic neck pain and C1-2 fusion patients. Spine 2008, 33:1018-1027.

25. Nieto R, Miro J, Huguet A: Disability in subacute whiplash patients: usefulness of the neck disability index. Spine 2008, 33:E630-635.

26. Chiu TT, Lam TH, Hedley AJ: Subjective health measure used on Chinese patients with neck pain in Hong Kong. Spine 2001, 26:1884-1889.

27. Lee KC, Chiu TT, Lam TH: Correlation between generic health status and region-specific functional measures on patients with neck pain. Int $\mathrm{J}$ Rehabil Res 2006, 29:217-220.

28. Leak AM, Cooper J, Dyer S, Williams KA, Turner-Stokes L, Frank AO: The Northwick Park Neck Pain Questionnaire, devised to measure neck pain and disability. Br J Rheumatol 1994, 33:469-474.

29. Pool JJ, Ostelo RW, Hoving JL, Bouter LM, de Vet HC: Minimal clinically important change of the Neck Disability Index and the Numerical Rating Scale for patients with neck pain. Spine 2007, 32:3047-3051.

30. Schmitt MA, de Wijer A, van Genderen FR, van der Graaf Y, Helders PJ, van Meeteren NL: The Neck Bournemouth Questionnaire cross-cultural adaptation into Dutch and evaluation of its psychometric properties in a population with subacute and chronic whiplash associated disorders. Spine 2009, 34:2551-2561.

31. Vos CJ, Verhagen AP, Koes BW: Reliability and responsiveness of the Dutch version of the Neck Disability Index in patients with acute neck pain in general practice. Eur Spine J 2006, 15:1729-1736.

32. Bolton JE, Humphreys BK: The Bournemouth Questionnaire: A short-form comprehensive outcome measure. II. Psychometric properties in neck pain patients. J Manipulative Physiol Ther 2002, 25:141-148.

33. Stewart M, Maher CG, Refshauge KM, Bogduk N, Nicholas M: Responsiveness of pain and disability measures for chronic whiplash. Spine 2007, 32:580-585

34. Jordan A, Manniche C, Mosdal C, Hindsberger C: The Copenhagen neck functional disability scale: A study of reliability and validity. J Manipulative Physiol Ther 1998, 21:520-527.

35. Salo P, Ylinen J, Kautiainen $H$, Arkela-Kautiainen M, Hakkinen A: Reliability and validity of the finnish version of the neck disability index and the modified neck pain and disability scale. Spine 2010, 35:552-556.

36. Wlodyka-Demaille S, Poiraudeau S, Catanzariti JF, Rannou F, Fermanian J, Revel M: French translation and validation of 3 functional disability scales for neck pain. Arch Phys Med Rehabil 2002, 83:376-382.

37. Martel J, Dugas C, Lafond D, Descarreaux M: Validation of the French version of the Bournemouth Questionnaire. I Canadian Chiropractic Association 2009, 53:102-110.

38. Scherer M, Blozik E, Himmel W, Laptinskaya D, Kochen MM, HerrmannLingen C: Psychometric properties of a German version of the neck pain and disability scale. Eur Spine J 2008, 17:922-929.

39. Trouli MN, Vernon HT, Kakavelakis KN, Antonopoulou MD, Paganas AN, Lionis CD: Translation of the Neck Disability Index and validation of the Greek version in a sample of neck pain patients. BMC Musculoskelet Disord 2008, 9.

40. Agarwal S, Allison GT, Agarwal A, Singer KP: Reliability and validity of the Hindi version of the Neck Pain and Disability Scale in cervical radiculopathy patients. Disabil Rehabil 2006, 28:1405-1411.

41. Mousavi SJ, Parnianpour M, Montazeri A, Mehdian H, Karimi A, Abedi M, Ashtiani AA, Mobini B, Hadian MR: Translation and validation study of the Iranian versions of the neck disability index and the neck pain and disability scale. Spine 2007, 32:E825-E831.

42. Monticone M, Baiardi P, Nido N, Righini C, Tomba A, Giovanazzi E: Development of the Italian version of the Neck Pain and Disability Scale, NPDS-I: cross-cultural adaptation, reliability, and validity. Spine 2008, 33: E429-434.

43. Lee H, Nicholson LL, Adams RD, Maher CG, Halaki M, Bae SS: Development and psychometric testing of Korean language versions of 4 neck pain and disability questionnaires. Spine 2006, 31:1841-1845.

44. Gonzalez T, Balsa A, Sainz de Murieta J, Zamorano E, Gonzalez I, MartinMola E: Spanish version of the Northwick Park Neck Pain Questionnaire: reliability and validity. Clin Exp Rheumatol 2001, 19:41-46. 
45. White $P$, Lewith $G$, Prescott $P$ : The core outcomes for neck pain: Validation of a new outcome measure. Spine 2004, 29:1923-1930.

46. Andrade Ortega JA, Delgado Martinez AD, Almecija Ruiz R: Validation of the Spanish version of the Neck Disability Index. Spine 2010, 35:E114-118.

47. Aslan E, Karaduman A, Yakut Y, Aras B, Simsek IE, Yagly N: The cultural adaptation, reliability and validity of neck disability index in patients with neck pain: a Turkish version study. Spine 2008, 33:E362-365.

48. Kose G, Hepguler S, Atamaz F, Oder G: A comparison of four disability scales for Turkish patients with neck pain. J Rehabil Med 2007, 39:358-362.

\section{Pre-publication history}

The pre-publication history for this paper can be accessed here: http://www.biomedcentral.com/1471-2288/11/87/prepub

doi:10.1186/1471-2288-11-87

Cite this article as: Schellingerhout et al:: Measurement properties of translated versions of neck-specific questionnaires: a systematic review. BMC Medical Research Methodology 2011 11:87.

\section{Submit your next manuscript to BioMed Central and take full advantage of:}

- Convenient online submission

- Thorough peer review

- No space constraints or color figure charges

- Immediate publication on acceptance

- Inclusion in PubMed, CAS, Scopus and Google Scholar

- Research which is freely available for redistribution

Submit your manuscript at www.biomedcentral.com/submit 